\title{
Estimation of Net Long wave Radiation in IRAQ
}

\author{
Dr. Waleed I . AL-Rijabo, Firas Hazim .AL-Harby \\ College of Education, Dept of physics Mosul University
}

\begin{abstract}
FAO-56 Model which is widely used in the world was used to estimate net long wave radiation (Rnl) in 19 weather stations spread in IRAQ for the time period(1980-2008). Simple linear regression equations were found between the mean monthly values of (Rnl) and the mean monthly values of: mean air temperature $\left(T_{\text {mean }}\right)$, relative humidity $(R H)$ and solar radiation ratio $(R s / R s o)$ for all stations which gave a highly correlation coefficients. For Iraq as a whole the correlation coefficients for these linear regression equations were $(0.816,-0.850,0.938)$ respectively. multiple regression equation was found between the mean monthly values of (Rnl) and the mean monthly values of all the following elements $\left[T_{\text {mean }}, R H, R s / R s o\right.$ ] for Iraq which gave a highly correlation coefficient reach (0.975).
\end{abstract}

\section{Introduction}

Long wave radiation (RL) represent the emitted radiation from the atmospheric contents and the earth surface with a wave length ranged between (4-100) micron ${ }^{[1]}$. Terrestrial radiation happened during the daytime and nighttime while solar radiation happened during the daytime only ${ }^{[2]}$. Cloud behavior look like black body in absorbing and emitting the radiation .Cloud base absorb a large quantity of terrestrial radiation and it will reradiate it toward the earth surface, so the net radiation lost from the earth surface is reduced in presence of cloud.

Incoming long wave radiation ( $R L \downarrow$ ) depend on air temperature and atmospheric emissivity .The atmospheric emissivity represent the effects of cloud amount, relative humidity , and the thermal composition of the atmosphere ${ }^{[3.4]}$. Outgoing long wave radiation (RL $\uparrow$ ) depend on surface emissivity and surface temperature ${ }^{[5]}$.Net long wave radiation $(\mathrm{Rnl})$ represent the difference between the incoming long wave radiation and the outgoing long wave radiation.

Normally the outgoing long wave radiation is greater than the incoming long wave radiation, so (Rnl) represent the energy losses . (Rnl) is rarely available because of economical and technical limitation ${ }^{[6]}$. Several models were deduced to estimate the net long wave radiation using meteorological parameters ${ }^{[7]}$. $\operatorname{Prta}^{[8]}$ and Perez-Garcia ${ }^{[9]}$ Found a mathematical models to estimate long wave radiation from mean air temperature and relative humidity under cloudless skies. Under cloudy sky the estimation of long wave radiation is more complicated and their mathematical models is limited ${ }^{[10,11]}$. In our research net long wave radiation was estimation using (FAO-56) model ${ }^{[1]}$ which is widely used in the world and represent the more accurate model among the other models .

\section{Objective of the research}

1- Estimation of the mean monthly values of net long wave radiation in (19) stations spread in IRAQ using FAO-56 model. The annual contour map of (Rnl) for lraq were also found .

2-Simple and Multiple regression equations between net long wave radiation and climatological elements were found

\section{Methodology}

From Iraqi meteorological Organization the different climatological elements needed for FAO-56 model were taken which represent (maximum air temperature, relative humidity and sun shine) during the period (1980-2008) for the stations (Zakho , Mosul, Erbil , Baag, Sulaimaniya , Kirkuk , Baiji ,Ana , Kalis , Baghdad, Rutba ,Kut, Nukhaib , Najaf, Amara, Samawa, Nasiriya , Basrah , Salman) .

The available measured solar radiation data were taken in (Mosul ,Kirkuk, Baghdad, Rutba and Nasiriya) stations . In the other stations solar radiation instrument is not available in it, so the mean monthly values of solar radiation is estimated using Glover model with local constants , the model was :

\section{$\operatorname{Rs}=\operatorname{Ra}[-0.847+1.259 \cos (\emptyset)+0.473(n / N)]$}

This model give a high accuracy where the Mean Absolute Error (\%MAE) between the estimated and measured value does not exceed $(4.3 \%)$. The values of net long wave radiation(Rnl) were found from (FAO-56)model for each of the selected stations.

The model :

$\mathrm{RnI}=\sigma\left[\frac{T^{4} \max , K+T^{4} \min , K}{2}\right]\left(0.34-0.14 \sqrt{e_{a}}\right)\left(1.35 \frac{\mathrm{Rs}}{\mathrm{Rso}}-0.35\right)$ 
Rnl : net long wave radiation in $\left(\mathrm{MJ} / \mathrm{m}^{2} . \mathrm{d}\right)$

$\mathbf{T}_{\min } \mathrm{k}, \mathbf{T}_{\max } \mathrm{k}$ : daily minimum and maximum air temperature in $(\mathrm{K})$.

Rs : short wave radiation in $\left(\mathrm{MJ} / \mathrm{m}^{2} . \mathrm{d}\right)$

Rso : clear-sky short wave radiation in $\left(\mathrm{MJ} / \mathrm{m}^{2} . \mathrm{d}\right)$

$\mathbf{e}_{\mathrm{a}}$ : actual vapor pressure in $(\mathrm{Kpa})$

б: Stefan -Boltzmann constant $\left[4.903 \times 10^{-9} \mathrm{MJ} \mathrm{K}^{-4} \mathrm{~m}^{-2} \mathrm{~d}^{-1}\right]$

Rso can be calculated form :

Rso $=\left(0.75+2 \times 10^{-5} \mathrm{z}\right) \mathrm{Ra}$

$\mathbf{Z}$ : elevation of station above mean sea level (m)

Ra: Extraterrestrial radiation in $\left(\mathrm{MJ} / \mathrm{m}^{2} . \mathrm{d}\right)$

In this research we find the mean monthly, seasonally and annually Long wave radiation for all stations. Annual contour map of (Rnl) for lraq were drawn, and then we find the mean annual value of (Rnl) from this map. Linear regression equations were found between $(\mathrm{Rnl})$ and each of the following climatic elements $\left[\mathrm{T}_{\text {mean }}, \mathrm{RH}\right.$, $\mathrm{Rs} / \mathrm{Rso}$ for all stations and for Iraq as a whole. Multiple regression equation were also found between the mean monthly values of (Rnl) and the mean monthly values of all the following climatic elements [ $T_{\text {mean }}, R H$, Rs/Rso] for Iraq as a whole . (GIS V -3.3), (surfer v.9.9),(Global mapper V.11) programs were used to find the contour map of (Rnl) and the area between the contour lines.

\section{1-Testing the accuracy of FAO-56 model .}

\section{Result and Discussions}

In order to test the accuracy of FAO-56 model in estimating the Rnl, a linear regression equation was established between the measured value of Rnl and the estimated value for Baghdad station. Fig (1) show this correlation .The figure demonstrate a highly positive correlation between the measured and estimated value of $\mathrm{Rnl}$, where the correlation coefficient was $(\mathrm{R}=0.92)$, and this indicate that the model is quite accurate.

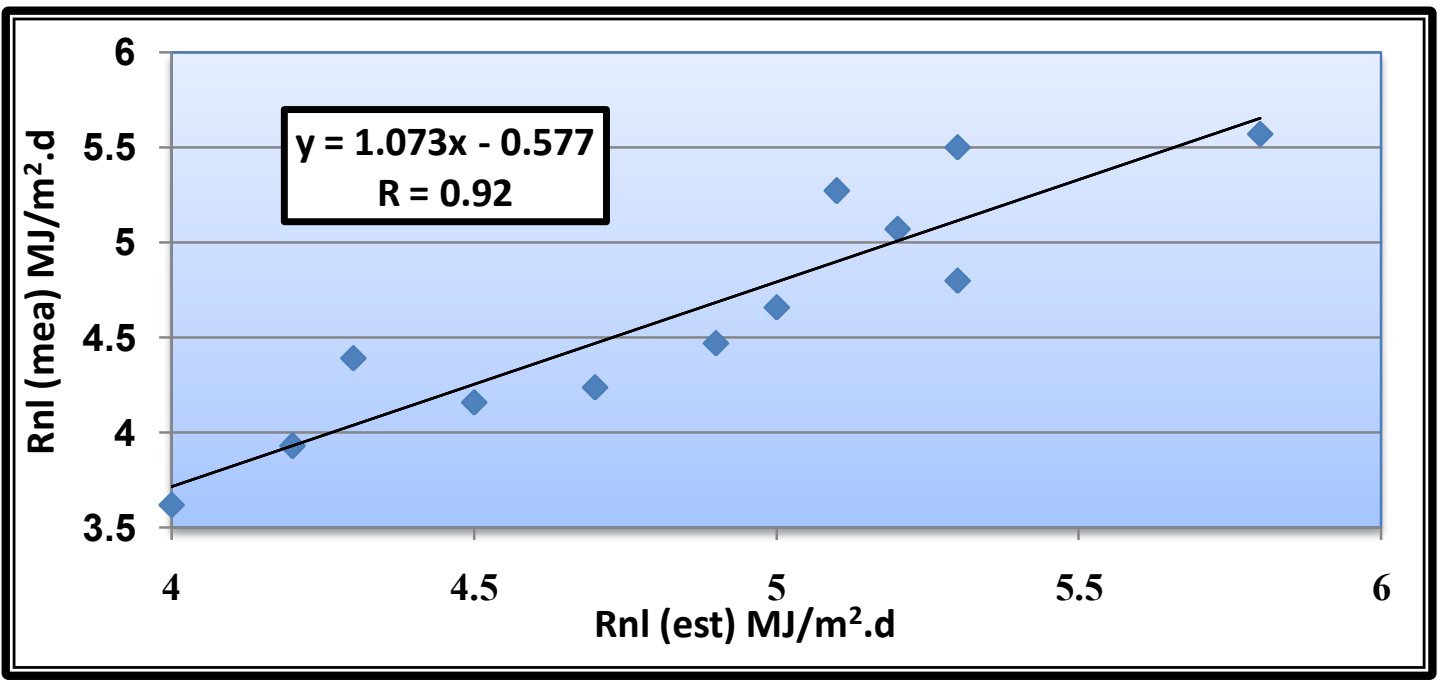

Fig(1): correlation between the measured and estimated value of Rnl for Bagdad city.

\section{2-Mean monthly values of net long wave radiation for all stations}

The values of net long wave radiation $(\mathrm{Rnl})$ varies according to latitude of stations, sun-path geometry , air temperature, presence of cloud, emissivity of the earth and atmosphere .

Table (1) show the mean monthly values of the net long wave radiation (Rnl) in $\left(\mathrm{MJ} / \mathrm{m}^{2} . \mathrm{d}\right)$ for all stations. We can deduce from the table that there is a spatial variation of ( $\mathrm{Rnl})$ where it increase from the north of Iraq toward the south, this is due to the increase of short wave radiation and air temperature from the north toward the south of Iraq. The minimum value of (Rnl) was obtained in Zakho and Mosul stations while the maximum values was obtained in Salman, Basrah and Samawa stations. December and January show the minmum values of (Rnl)in all stations which ranged between $(2.12-4.29) \mathrm{MJ} / \mathrm{m}^{2} . \mathrm{d}$. June and July show the maximum values of (Rnl) which ranged between $(4.33-7.31) \mathrm{MJ} / \mathrm{m}^{2} . \mathrm{d}$. The higher values of (Rnl)in summer months in comparison with the winter months depend on the values of maximum and minimum air temperature, relative humidity, vapor pressure, and the solar radiation ratio (Rs/Rso) in summer months in comparison with the winter months. 
Table (1) : Mean monthly values of $(\mathrm{Rnl})$ in $\mathrm{MJ} / \mathrm{m}^{2} . \mathrm{d}$ for all stations

\begin{tabular}{|c|c|c|c|c|c|c|c|c|c|c|c|c|}
\hline Stations & JAN & FEB & MAR & APR & MAY & JUN & JUL & AUG & SEP & OCT & Nov & DEC \\
\hline Zakho & 2.12 & 2.32 & 2.38 & 2.75 & 3.52 & 4.89 & 5.42 & 5.44 & 5.35 & 3.77 & 2.63 & 2.28 \\
\hline Mosul & 2.14 & 2.79 & 2.71 & 2.85 & 3.56 & 4.33 & 4.39 & 4.34 & 4.39 & 3.47 & 2.90 & 2.15 \\
\hline Erbil & 2.44 & 2.84 & 2.86 & 2.76 & 3.55 & 4.78 & 4.66 & 5.03 & 4.94 & 4.06 & 3.18 & 2.33 \\
\hline Baag & 2.38 & 2.42 & 3.23 & 3.38 & 4.02 & 4.82 & 4.97 & 4.95 & 4.70 & 4.00 & 3.32 & 2.37 \\
\hline Sulaiman & 2.62 & 2.58 & 2.57 & 3.08 & 3.95 & 5.45 & 5.71 & 5.70 & 5.51 & 4.11 & 3.22 & 2.76 \\
\hline Kirkuk & 2.69 & 2.94 & 3.04 & 3.23 & 4.07 & 4.93 & 5.21 & 5.24 & 5.37 & 4.47 & 3.49 & 2.69 \\
\hline Baiji & 2.88 & 3.36 & 3.33 & 3.33 & 3.97 & 4.82 & 4.75 & 4.82 & 4.65 & 3.82 & 3.44 & 2.77 \\
\hline Ana & 3.12 & 3.61 & 3.74 & 3.71 & 4.20 & 5.25 & 5.02 & 5.20 & 4.98 & 4.19 & 3.60 & 2.80 \\
\hline Khalis & 3.08 & 3.43 & 3.61 & 3.54 & 3.97 & 4.61 & 4.38 & 4.49 & 4.40 & 3.86 & 3.67 & 3.09 \\
\hline Baghdad & 3.93 & 4.39 & 4.24 & 4.47 & 4.80 & 5.57 & 5.50 & 5.27 & 5.07 & 4.66 & 4.16 & 3.62 \\
\hline Rutba & 3.25 & 3.80 & 4.18 & 4.58 & 4.97 & 5.90 & 5.95 & 5.65 & 5.69 & 5.03 & 4.22 & 3.51 \\
\hline Kut & 3.76 & 4.08 & 4.01 & 3.98 & 4.65 & 5.75 & 5.67 & 5.65 & 5.53 & 4.78 & 4.11 & 3.70 \\
\hline Nukhaib. & 4.11 & 4.52 & 4.50 & 4.58 & 4.94 & 6.04 & 6.12 & 5.96 & 5.81 & 4.86 & 4.48 & 3.73 \\
\hline Najaf & 3.97 & 4.34 & 4.22 & 4.28 & 4.65 & 5.90 & 6.10 & 6.31 & 5.64 & 4.81 & 4.28 & 3.83 \\
\hline Amara & 3.71 & 4.14 & 3.80 & 4.00 & 4.42 & 5.61 & 5.61 & 5.65 & 5.44 & 4.62 & 4.07 & 3.64 \\
\hline Samawa & 4.23 & 4.46 & 4.40 & 4.45 & 4.82 & 6.02 & 6.15 & 6.11 & 5.71 & 5.02 & 4.46 & 3.97 \\
\hline Dasiriva & 3.73 & 4.31 & 4.14 & 4.14 & 4.32 & 4.62 & 4.91 & 4.93 & 5.02 & 4.54 & 3.99 & 3.56 \\
\hline Basrah & 4.00 & 4.49 & 4.35 & 4.33 & 4.96 & 5.97 & 5.72 & 5.68 & 5.67 & 4.87 & 4.44 & 4.11 \\
\hline Salman & 4.29 & 4.67 & 4.66 & 5.24 & 5.32 & 6.79 & 7.31 & 7.49 & 6.74 & 5.68 & 4.94 & 4.13 \\
\hline
\end{tabular}

\section{Mean seasonally and annually net long wave radiation}

From table(2) we can see that the minimum values of (Rnl) during the winter and spring seasons was obtained in Zakho and Mosul stations

which is ranged between (2.24 -3.06) $\mathrm{MJ} / \mathrm{m}^{2} . \mathrm{d}$. During summer season the minimum values of (Rnl) was obtain in Mosul and Khalis stations, which is ranged between ( $4.35-4.49$ ) MJ $/ \mathrm{m}^{2} . \mathrm{d}$.

The minimum value of $(\mathrm{Rnl})$ in winter season was obtained in Mosul station which reach ( 3.58$) \mathrm{MJ} / \mathrm{m}^{2} . \mathrm{d}$.

The maximum value of (Rnl) during all seasons are obtained in Salman ,Samawa and Basrah stations, and their values in these stations are :

$(4.36,4.22,4.20) \mathrm{MJ} / \mathrm{m}^{2} . \mathrm{d}$.in winter season ,

$(5.07,4.56,4.55) \mathrm{MJ} / \mathrm{m}^{2} . \mathrm{d}$.in spring season

$(7.20,6.10,5.79) \mathrm{MJ} / \mathrm{m}^{2}$. d.in summer season

$(5.79,5.06,4.99) \mathrm{MJ} / \mathrm{m}^{2} . \mathrm{d}$.in autumn season

Table(2):Mean seasonally and annually values of Rnl for all stations

\begin{tabular}{|c|c|c|c|c|c|}
\hline Months & Winter & Spring & Summer & Autumn & $\begin{array}{l}\text { Annual } \\
\text { average }\end{array}$ \\
\hline Zakho & 2.24 & 2.88 & 5.25 & 3.92 & 3.57 \\
\hline Mosul & 2.36 & 3.04 & 4.35 & 3.58 & 3.33 \\
\hline Erbel & 2.54 & 3.06 & 4.82 & 4.06 & 3.62 \\
\hline Baag & 2.39 & 3.54 & 4.91 & 4.01 & 3.71 \\
\hline Sulaimaniva & 2.65 & 3.20 & 5.62 & 4.28 & 3.94 \\
\hline Kirkuk & 2.78 & 3.45 & 5.13 & $\overline{4.44}$ & 3.95 \\
\hline Baiji & 3.00 & 3.54 & 4.79 & 3.97 & 3.83 \\
\hline Ana & 3.18 & 3.89 & 5.16 & 4.26 & 4.12 \\
\hline Khalis & 3.20 & 3.71 & 4.49 & 3.97 & 3.84 \\
\hline Baghdad & 3.98 & 4.50 & 5.45 & 4.63 & 4.64 \\
\hline Rutba & 3.52 & 4.58 & 5.84 & 4.98 & 4.73 \\
\hline Kut & 3.84 & 4.22 & 5.69 & 4.80 & 4.64 \\
\hline Nukhaib & 4.12 & 4 & 6.04 & 5.05 & 4 \\
\hline Najaf & 4.05 & 4.38 & 6.11 & 4.91 & 4.86 \\
\hline Amara & 3.83 & $4 \overline{4.07}$ & 5.62 & $4 \overline{4.71}$ & 4.56 \\
\hline Samawa & 4.22 & 4.56 & 6.10 & 5.06 & 4.98 \\
\hline Nasiriya & 3.87 & 4.20 & 4.82 & 4.52 & 4.35 \\
\hline Basrah & 4.20 & 4.55 & 5.79 & 4.99 & 4.88 \\
\hline Salman & 4.36 & 5.07 & 7.20 & 5.79 & 5.60 \\
\hline
\end{tabular}

The table (2) show also the mean annual values of (Rnl), which can arrange from the higher value to the lower value as $(5.6,4.98,4.97,4.88,4.86,4.734 .64,4.56,4.35,4.12,3.95,3.94,3.84,3.83,3.71,3.62,3.57$, $3.33) \mathrm{MJ} / \mathrm{m}^{2} . \mathrm{d}$. in the stations ( salman, samawa, nukkhaib ,basrah, najaf , ratba ,kut , baghdad , amara, nasiriya , ana , kirkuk, sulaimaniya , khalis , baji , Erbil , Zakhe, mosul ) respectively 
Fig(2) show the contour lines of the mean annul values of ( $\mathrm{Rnl})$ in $\mathrm{MJ} / \mathrm{m}^{2}$.d. on Iraqi map . we can deduce from the figure :

1-The mean annual value of (Rnl) for the whole of Iraq was (4.53) $\mathrm{MJ} / \mathrm{m}^{2} . \mathrm{d}$.

2-The contour lines for (Rnl) was nearest to each other .

3-The number of contour lines obtained from the map was (7) with contour interval $(0.3) \mathrm{MJ} / \mathrm{m}^{2} . \mathrm{d}$, and there is no closed circle in the map

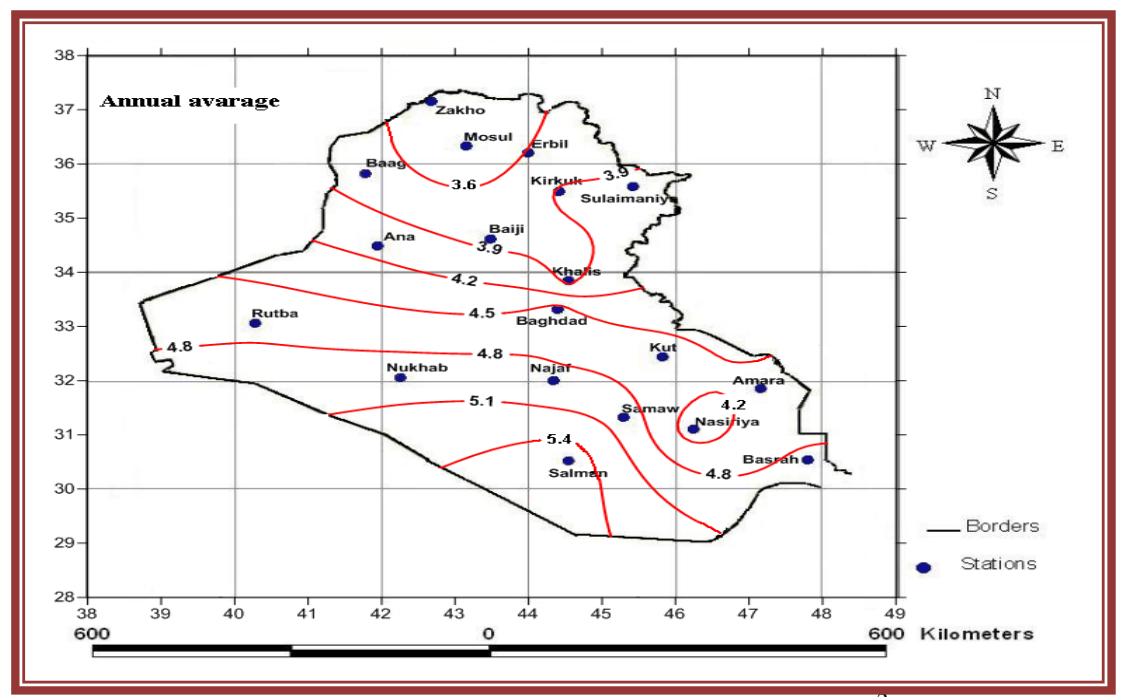

Fig(2) contour lines of the mean annul values of (Rnl)in $\mathrm{MJ} / \mathrm{m}^{2}$.d. on Iraqi map.

4-correlations between mean monthly values of $(\mathrm{Rnl})$ and the mean monthly values of each of $\left(\mathrm{T}_{\text {mean }}, \mathrm{RH}\right.$, Rs/Rso) for all stations .

Table (3) show the correlation coefficients between the mean monthly values of (Rnl) and the mean monthly value of $\left(\mathrm{T}_{\text {mean }}\right)$ for all stations .

The table show a highly positive correlations between the two variables. The maximum value of the correlation coefficient $(R)$ was obtain in Baag station $(R=0.986)$, while Nasiriya station gave the minimum value of $(R)$ through all stations and its value was ( 0.847 ). Mean air temperature is a fundamental element in computing net long wave radiation, where the emissivity of the earth surface, and the atmosphere depend mainly on their temperature .The emissivity increase with the increasing value of the temperature. These correlations are useful for the forecasting of (Rnl) from the value of mean air temperature which is often measured in all meteorological stations.

Table (3) : correlations between mean monthly values of net long wave radiation (Rnl) and mean air temperature $\left(\mathrm{T}_{\text {mean }}\right)$ for all stations .

\begin{tabular}{|c|c|c|}
\hline Stations & Rnl \& $\mathbf{T}_{\text {mean }}$ & $\mathbf{R}$ \\
\hline Zakho. & Rnl $=0.130 T_{\text {mean }}+1.010$ & 0.969 \\
\hline Mosul & $\mathrm{Rnl}=0.082 \mathrm{~T}_{\text {mean }}+1.661$ & 0.966 \\
\hline Erbil & $\mathrm{Rnl}=0.093 \mathrm{~T}_{\text {mean }}+1.667$ & 0.949 \\
\hline Baag & $\mathrm{Rnl}=0.102 \mathrm{~T}_{\text {mean }}+1.610$ & 0.986 \\
\hline Sulaimaniya & Rnl $=0.125 \mathrm{~T}_{\text {mean }}+1.591$ & 0.972 \\
\hline Kirkuk & $\mathrm{Rnl}=0.099 \mathrm{~T}_{\text {mean }}+1.707$ & 0.960 \\
\hline Baiji & $\mathrm{Rnl}=0.072 \mathrm{~T}_{\text {mean }}+2.189$ & 0.954 \\
\hline Ana & Rnl $=0.080 \mathrm{~T}_{\text {mean }}+2.455$ & 0.944 \\
\hline Khalis & $\mathrm{Rnl}=0.055 \mathrm{~T}_{\text {mean }}+2.631$ & 0.949 \\
\hline Baghdad & $\mathrm{Rnl}=0.061 \mathrm{~T}_{\text {mean }}+3.243$ & 0.940 \\
\hline Rutba & $\mathrm{Rnl}=0.103 \mathrm{~T}_{\text {mean }}+2.696$ & 0.984 \\
\hline Kut & $\mathrm{Rnl}=0.078 \mathrm{~T}_{\text {mean }}+2.733$ & 0.929 \\
\hline Nukhaib. & $\mathrm{Rnl}=0.081 \mathrm{~T}_{\text {mean }}+3.171$ & 0.936 \\
\hline Najaf & $\mathrm{Rnl}=0.084 \mathrm{~T}_{\text {mean }}+2.811$ & 0.912 \\
\hline Amarah & $\mathrm{Rnl}=0.074 \mathrm{~T}_{\text {mean }}+2.696$ & 0.917 \\
\hline Samawah & $\mathrm{Rnl}=0.075 \mathrm{~T}_{\text {mean }}+3.115$ & 0.912 \\
\hline Nasiriya & $\mathrm{Rnl}=0.034 \mathrm{~T}_{\text {mean }}+3.429$ & 0.847 \\
\hline Basrah & $\mathrm{Rnl}=0.067 \mathrm{~T}_{\text {mean }}+3.135$ & 0.918 \\
\hline salman & $\mathrm{Rnl}=0.113 \mathrm{~T}_{\text {mean }}+2.773$ & 0.924 \\
\hline
\end{tabular}


Table(4) show the correlations between the mean monthly values of (Rnl) and the mean monthly values of Relative Humidity ( $\mathrm{RH}$ ) for all stations. The table show a highly negative correlations between the two variables. The correlations coefficients of these correlations was ranged between $(-0.891)$ in Nasiriya station and ( -0.993 ) in Zakho station .

Relative Humidity play an important role in computing ( $\mathrm{Rnl}$ ) where it affect mainly the values of the actual vapour pressure ( ea ) used in the equation of ( Rnl ).

The highly negative correlations show that the increasing ( $\mathrm{RH}$ ) in winter months leads to reduce the value of ( $\mathrm{Rnl}$ ), while in summer months the reducing values of ( RH ) lead to increasing values of ( Rnl ).

These correlations are useful in the forecasting of ( $\mathrm{Rnl}$ ) from the measured value of ( $\mathrm{RH}$ ) which is available in all meteorological stations.

Table (4) : correlations between the mean monthly values of ( Rnl ) and the mean monthly of ( RH ) in all stations .

\begin{tabular}{|c|c|c|}
\hline Stations & Rnl \& RH \% & $\mathbf{R}$ \\
\hline Zakho & $\mathrm{Rnl}=-0.071 \mathrm{RH}+6.715$ & -0.993 \\
\hline Mosul & $\mathrm{Rnl}=-0.040 \mathrm{RH}+5.42 \mathrm{~s}$ & -0.985 \\
\hline Erbil & $\mathrm{Rnl}=-0.058 \mathrm{RH}+6.268$ & -0.971 \\
\hline Baag & $\mathrm{RnI}=-0.051 \mathrm{RH}+6.170$ & -0.985 \\
\hline Sulaimaniya & $\mathrm{Rnl}=-0.062 \mathrm{RH}+6.796$ & -0.973 \\
\hline Kirkuk & $\mathrm{Rnl}=-0.052 \mathrm{RH}+6.375$ & -0.965 \\
\hline Baiji & $\mathrm{Rnl}=-0.039 \mathrm{RH}+5.750$ & -0.953 \\
\hline Ana & $\mathrm{Rnl}=-0.040 \mathrm{RH}+6.044$ & -0.942 \\
\hline Khalis & Rnl $=-0.031$ RH +5.509 & -0.953 \\
\hline Baghdad & Rnl $=-0.034 \mathrm{RH}+6.158$ & -0.944 \\
\hline Rutba & $\mathrm{Rnl}=-0.056 \mathrm{RH}+7.251$ & -0.979 \\
\hline Kut & $\mathrm{Rnl}=-0.039 \mathrm{RH}+6.477$ & -0.929 \\
\hline Nukhaib & $\mathrm{RnI}=-0.044 \mathrm{RH}+6.735$ & -0.915 \\
\hline Najaf & $\mathrm{Rnl}=-0.044 \mathrm{RH}+6.738$ & -0.898 \\
\hline Amarah & $\mathrm{Rnl}=-0.041 \mathrm{RH}+6.439$ & -0.920 \\
\hline Samawah & Rnl $=-0.043 \mathrm{RH}+6.771$ & -0.893 \\
\hline Nasiriya & $\mathrm{Rnl}=-0.024 \mathrm{RH}+5.370$ & -0.891 \\
\hline Basrah & Rnl $=-0.037$ RH +6.457 & -0.912 \\
\hline salman & $\mathrm{Rnl}=-0.064 \mathrm{RH}+7.648$ & -0.903 \\
\hline
\end{tabular}

Table (5) show the correlations between the mean monthly values of (Rnl) and the mean monthly values of (Rs / Rso) in all stations .

The table show a highly positive correlations between the two variables. The correlations coefficients in all stations except Nasiriyia station was ranged between $(0.936-0.997)$. In Nasiriys station $\mathrm{R}=(0.793)$.

Rs/Rso was essesential in computing ( Rnl ) where the increasing values of Rs / Rso lead to increasing value of ( $\mathrm{Rnl})$.

Table (5) : correlations between the mean monthly values of ( Rnl ) and the mean monthly values of ( Rs / Rso ) in all stations .

\begin{tabular}{|c|c|c|}
\hline $\begin{array}{l}\text { Corrl } \\
\text { Stations }\end{array}$ & Rnl \&(Rs/Rso) & $\mathbf{R}$ \\
\hline Zakho & $\mathrm{Rnl}=13.72(\mathrm{Rs} / \mathrm{Rso})-4.804$ & 0.988 \\
\hline Mosul & $\mathrm{Rnl}=11.72(\mathrm{Rs} / \mathrm{Rso})-3.96 \mathrm{~S}$ & 0.984 \\
\hline Erbil & $\mathrm{Rnl}=12.21(\mathrm{Rs} / \mathrm{Rso})-4.086$ & 0.997 \\
\hline Baag & $\mathrm{Rnl}=11.50(\mathrm{Rs} / \mathrm{Rso})-3.786$ & 0.994 \\
\hline Sulaimaniya & $\mathrm{Rnl}=14.30(\mathrm{Rs} / \mathrm{Rso})-5.342$ & 0.991 \\
\hline Kirkuk & $\mathrm{Rnl}=12.51(\mathrm{Rs} / \mathrm{Rso})-4.466$ & 0.990 \\
\hline Baiji & $\mathrm{Rnl}=11.00(\mathrm{Rs} / \mathrm{Rso})-3.709$ & 0.986 \\
\hline Ana & $\mathrm{Rnl}=12.50(\mathrm{Rs} / \mathrm{Rso})-4.605$ & 0.980 \\
\hline Khalis & $\mathrm{Rnl}=\mathbf{8 . 0 8 7}(\mathrm{Rs} / \mathrm{Rso})-1.908$ & 0.987 \\
\hline Baghdad & $\mathrm{Rnl}=12.21(\mathrm{Rs} / \mathrm{Rso})-4.683$ & 0.952 \\
\hline Rutba & $\mathrm{Rnl}=12.88(\mathrm{Rs} / \mathrm{Rso})-4.904$ & 0.991 \\
\hline Kut & $\mathrm{Rnl}=13.46(\mathrm{Rs} / \mathrm{Rso})-5.680$ & 0.985 \\
\hline Nukhaib & $\mathrm{Rnl}=15.39\left(\mathrm{Rs} / \mathrm{Rso}_{\mathrm{s}}\right)-6.729$ & 0.936 \\
\hline Najaf & $\mathrm{Rnl}=15.81(\mathrm{Rs} / \mathrm{Rso})-7.215$ & 0.982 \\
\hline Amarah & Rnl $=12.51($ Rs/Rso $)-5.007$ & 0.983 \\
\hline Samavah & $\mathrm{Rnl}=14.37(\mathrm{Rs} / \mathrm{Rso})-6.247$ & 0.970 \\
\hline Nasiriva & Rnl $=11.97(\mathrm{Rs} / \mathrm{Rso})-4.319$ & 0.793 \\
\hline Basrah & $\mathrm{Rnl}=13.91(\mathrm{Rs} / \mathrm{Rso})-6.040$ & 0.939 \\
\hline salman & $\mathrm{Rnl}=23.24(\mathrm{Rs} / \mathrm{Rso})-12.44$ & 0.978 \\
\hline
\end{tabular}


Figures $(3,4,5)$ show the correlations between ( $\mathrm{Rnl})$ and each of $\left(\mathrm{T}_{\text {mean }}, \mathrm{RH}, \mathrm{Rs} / \mathrm{Rso}\right)$ for the whole of Iraq .

Fig (3) show a highly positive correlations between ( $\mathrm{Rnl}$ ) and ( $\mathrm{T}_{\text {mean }}$ ) for Iraq, where the values of ( $\mathrm{R}$ ) for this correlations reach $(0.816)$.

The correlations obtained was :

$$
\text { Rnl }=0.089 T_{\text {mean }}+2.316
$$

Fig (4) show a highly negative correlations between ( Rnl ) and ( RH ) for Iraq, where the values of ( R ) for this correlations reach $(-0.850)$. The correlations obtained was :

$$
\text { Rnl = - 0.05RH + 6.573 }
$$

Fig (5) show a highly positive correlations between ( $\mathrm{Rnl}$ ) and( Rs/Rso ) for Iraq, where the values of ( R ) for this correlations reach $(0.938)$ The correlations obtained was :

$$
\text { Rnl = 11.41Rs/Rso - } 3.826
$$

These there correlations are very important in forecasting of ( Rnl ) in any region in Iraq .

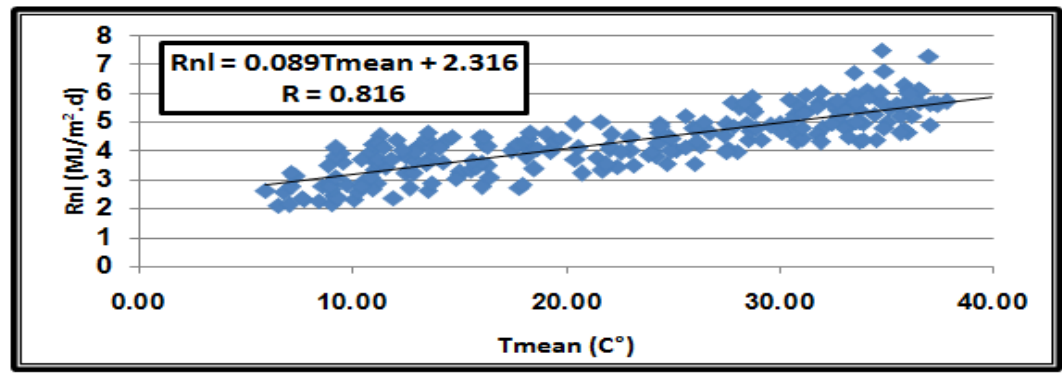

Fig (3): Correlation between $\mathrm{Rnl}$ and $\mathrm{T}_{\text {mean }}$ for IRAQ

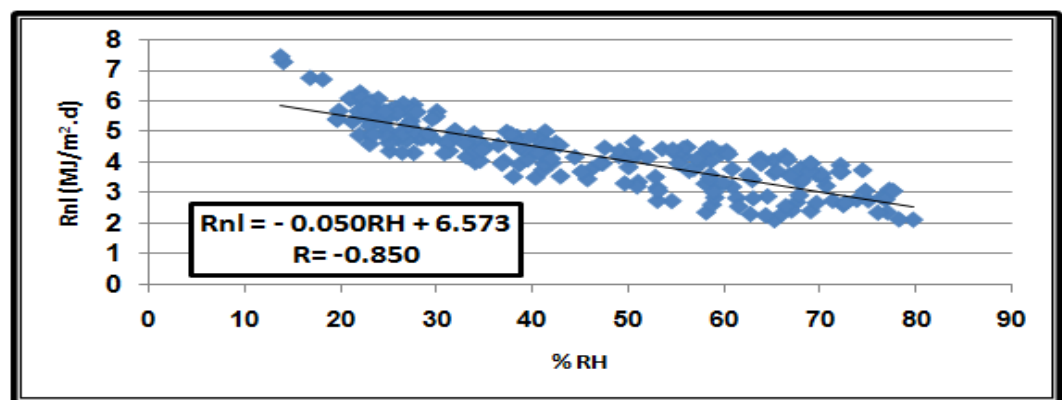

Fig (4) :Correlation between Rnl and RH for IRAQ

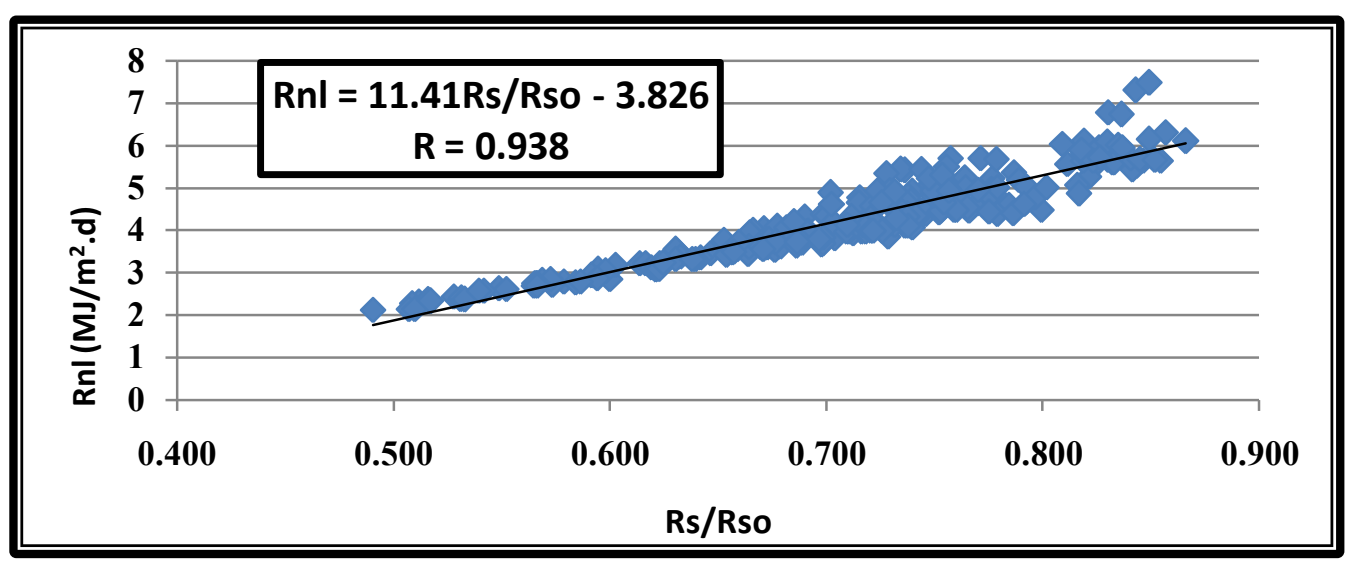

Fig(5) :Correlation between Rnl and Rs/Rso for IRAQ

Multiple correlation was obtained between $(\mathrm{Rnl})$ and $\left(\mathrm{T}_{\text {mean }}, \mathrm{RH}, \mathrm{Rs} / \mathrm{Rso}\right)$. This multiple correlations was : Rnl=0.7-3.98 $\times 10^{-2} \mathbf{T}_{\text {mean }}-3.95 \times 10^{-2}$ RH+8.811 ( Rs/Rso)

The correlation coefficient of this multiple correlation was ( 0.975$)$, which indicate the accuracy of this correlation. 


\section{Conclusion}

A clear spatial and temporal variation of ( Rnl ) was obtained for the different regions of Iraq. The mean annual value of $(\mathrm{Rnl})$ obtained was $(4.53) \mathrm{MJ} / \mathrm{m}^{2} . \mathrm{d}$. The simple linear regression equations indicate a highly correlation between the mean monthly values of ( $\mathrm{Rnl})$ and each of ( $\left.\mathrm{T}_{\mathrm{mem}}, \mathrm{RH}, \mathrm{Rs} / \mathrm{Rso}\right)$ in all stations . For Iraq as whole these correlations gave a values of $(\mathrm{R})$ reach is $[0.816,0.850,0.938)$ respectively . Multiple regression equation between the mean monthly values of (Rnl) and the mean monthly values of ( $\mathrm{T}_{\text {mean }}, \mathrm{RH}, \mathrm{Rs} / \mathrm{Rso}$ ) was obtained for Iraq as a whole, which is :

\section{Rnl=0.7-3.98 $\times 10^{-2} \mathrm{~T}_{\text {mean }}-\mathbf{- 3 . 9 5} \times 10^{-2} \mathrm{RH}+8.811$ ( Rs/Rso)}

This correlation gave a high value of $\mathrm{R}$ which reach ( 0.975 ) and this indicate the accuracy of this correlation .

\section{References}

[1]. Dharmaratine,A.,Chen,A .(1999) "Estimating Daytime Net Radiation Using Routine Meteorological Data in Jamaica " Caribbean Journal of Science, Vol. 35, No. 1-2, 132-141.

[2]. http://www.arts.kufauniv.com/teaching/go/samir\%20hadi/ lectures. html

[3]. Roger ,G. and Richard, (2003), Atmosphere, Weather and Climate, 8 th ed., J.chorley Route ledge ,Tayler and Francis group, pp 421.

[4]. Richard, A. (1997), Meteorology, 7 th ed. By prentice Hall, Inc 'pp 486.

[5]. Muhammad , I , (1983) " An Introduction To Solar Radiation " Academic press Canada

[6]. Samani ,Z ., Bawazir , A .;Bleiweiss ,M ;; Skaggs ,R .; Tran ,V(2007). "Estimating Daily Net Radiation over Vegetation Canopy through Remote Sensing and Climatic Data" Journal of Irrigation and Drainage engineering .pp291- 297.

[7]. Ogolo, E . and Falodun, S (2007),"Diurnal and Seasonal varations of Global Solar Radiation at Akure",South-Western Nigeria, Journal of Engineering and Applied Sciences 2(1):pp.125-128 .

[8]. Prata, A.J., (1996). "A new long-wave formula for estimating downward clear-sky radiation at the surface". Q. J. R. Meteorol. Soc. $122,1127-1151$.

[9]. Perez-Garcia, M., (2004)." Simplified modeling of the nocturnal clear sky atmospheric radiation for environmental applications". Ecol Model. 180, 395-406.

[10]. Crawford,T.M.,Duchon,C.E.,(1999). "An improved parameterization for estimating effective atmospheric emissivity for use in calculat- ing daytime down welling long-wave radiation". J. Appl. Meteorol. 38, 474-480.

[11]. Sridhar, V., Elliott, R.L., (2002). "On the development of a simple downwelling long-wave radiation scheme". Agric. Forest Meteorol. 112, 237-243.

[12]. Allen , R. G., Pereira, L.S ., Raes , D ., Smith , M (1998)."Crop evapotranspiration - Guidelines for computing crop water requirements"FAO-56 Irrigation and drainage paper 56, FAO Rome,Italy.CH3. PP(45-53). 